\title{
Retooling Assessment Procedures for Skill-based Health Education for Young People in Nigeria: Implications for 21st Century Educational Assessment
}

\author{
Francisca Chika Anyanwu*, Okeke Sylvester Reuben
}

Department of Human Kinetics and Health Education, University of Ibadan, Nigeria

Copyright (C) 2016 by authors, all rights reserved. Authors agree that this article remains permanently open access under the terms of the Creative Commons Attribution License 4.0 International License

\begin{abstract}
Skill-based Health Education is an approach to Health Education that is effective, interactive, engaging and meaningful. It focuses on skills and functional knowledge of health issues within a society. The importance of Health Education cannot be overemphasized as it plays significant role in preventing disease, prolonging life and protecting health. The extent to which the objectives of school Health Education can be realized is closely tied to assessment procedures that will be effective in assessing the skills taught. This is because a critical role assessment plays is to serve as a tool to support instructional processes. In a century characterized by explosion of knowledge as well as emerging challenges, skill-based Health Education has evolved as a responsive tool to surmounting the myriads of health challenges in this century. There is therefore an overwhelming need for a paradigm shift in the assessment procedures of school Health Education to critically evaluate the ability of learners to apply the skills in addressing contemporary societal health challenges. This paper attempts to propose appropriate assessment procedures for skill-based Health Education in Nigerian schools.
\end{abstract}

Keywords Health, Education, Assessment, Skill

\section{Introduction}

\section{Health Education and Skill-based Health Education}

Skill-based Health Education is an approach to Health Education that is effective, interactive, engaging and meaningful. It focuses on skills and functional knowledge of health issues within a society. Health Education is a vital element of preventive medicine aimed at equipping individuals with requisite knowledge, attitude and skills to protect and promote personal and community health. The importance of Health Education cannot be overemphasized as it plays significant role in preventing disease, prolonging life and protecting health. The extent to which the objectives of school Health Education can be realized is strongly tied to appropriate assessment procedures and tools.

Health Education has been defined as any combination of learning experiences designed to facilitate voluntary action conducive to health[1]. Combination in this definition emphasizes the importance of matching the multiple determinants of behaviour with multiple learning experiences or educational experiences. Designed distinguishes health education from incidental learning experiences as a systematically planned activity. Facilitate means predispose, enable and reinforce. Voluntary means without coercion, with full understanding and acceptance of the purposes of the action. Action means behavioral steps taken by an individual, group, or community to achieve an intended health effect. All the components of Health Education definition as identified by Green and Kreuter [1] are all vital aspects of aspirations of educational endeavor in the Twenty-First Century.

Health education therefore provides the consciousness-raising, concern-arousing, action-stimulating impetus for public involvement and commitment to social reform. It emphasizes the imparting of accurate information to set the stage for the adoption of sound health practices or the abandonment of poor ones. It focuses on acquainting people with the causes of disease, on health practices to reduce and avoid risk and on ways to detect a developing problem. According to Green and Kreuter [1], the defining characteristic of health education is the voluntary participation of learners in determining their own health practices. The authors argue that, "cognitive and behavioral changes depend on the degree of active rather than passive participation of the learner."

A broad purpose of health education therefore is not only to increase knowledge about personal health behaviour but also to develop skills that demonstrate the political feasibility and organizational possibilities of various forms of action to address social, economic and environmental determinants of health. Clarke [2] believes that one of the goals of health education is to produce health literacy. This occurs by fostering: 
- the capacity of individuals to obtain, interpret and understand health information and services (impart knowledge)

- competence to use such information and services in ways which enhance/maintain health of self and family members (developing decision-making skills).

Health education therefore provides the consciousness-raising, concern-arousing, action-stimulating impetus for public involvement and commitment to social reform. It emphasizes the imparting of accurate information to set the stage for the adoption of sound health practices or the abandonment of poor healthy practices. It focuses on acquainting people with the causes of disease, risk reduction and avoidance and preventing diseases occurrence.

Due to the myriads of health challenges posed by Twenty-First Century advancement and civilizations, skill-based Health Education was conceptualized to move the term from its traditional conceptualization of health knowledge and attitude to demonstration of vital skills; cognitive, social and manipulative, that could help in the attainment of the goals of Health Education. Skills-based health education uses a combination of participatory learning experiences that aims to develop knowledge, attitudes and especially skills needed to take positive actions to create healthy lifestyles and conditions [3]. It addresses real life applications of essential knowledge, attitudes and skills, and uses interactive teaching and learning methods. As a school based programme, the extent to which appropriate assessment techniques can improve the utility of the programme cannot be overemphasized. Unfortunately, present assessment tests are knowledge based and this adversely affects the utility of skill based health education. Providing a variety of assessment strategies that go beyond knowledge tests can assist teachers and other facilitators of learning to monitor progress of the learners, as part of routine good educational practice.

\section{Concept of Assessment}

Assessment as a universal construct in educational practice, according to Kizlik [4] is a process by which information is obtained relative to some known educational objective or goal in order to monitor progress and make decisions. In Nigeria, just as in other climes, assessment plays a crucial role in the educational system. Classroom-based assessments have proven to be an effective means through which students get feedback on how well they have performed and where they need to develop further understanding. Moreover, assessment has also been used to support instructional decisions aimed at reinforcing learning processes as well as monitoring students' progress. Equally important, is the evaluative role that assessment plays on the educational system as a whole. Large-scale summative assessments are influential levers on Nigeria's educational policy. Results of the examinations reflect the state of the Nigerian educational system - the quality of schools, teachers and other educational facilities. It is also used to determine the level of fund/resources required to get suitable educational results as well as whether students can advance to higher education among others.

\section{Assessment Challenges of the Twenty-first Century and Skill-based Health Education in Nigeria}

Assessment has always been an integral part of teaching and learning and will continue to be. However, the peculiarities of the Twenty-First Century have profound implications for assessment, particularly at the classroom instructional level. The century is a technology and media-driven century, marked by rapid advancement in Information and Communication Technology (ICT), which has reshaped the nature of learning and how work is conducted. The century is also characterized by global competition and access to an abundance of information. In fact, Lyman and Varian [5] estimated that in only three years, from 1999 to 2002, the amount of new information produced in the entire world approximately equaled the amount produced in the entire history of the world previously. The world's information is more than doubling every two years [6]. Therefore, success in the Twenty-First Century requires students to be able to process information (including information gathering, analysis, synthesis and evaluation), think critically, frame and solve non-routine problems, collaborate and connect through technology among others. These characteristics call for a paradigm shift in assessment strategies considering that the current assessment landscape in Nigeria may be deficient in measuring these Twenty-First Century learning outcomes which educational reformers are championing. The present assessment technique is largely characterized by assessment of knowledge and they are mainly 'paper and pen' based test. An effective assessment tool and procedure must assess knowledge, attitude and skill. An advocacy for the evolution of such tools and procedures is the main focus of this essay.

In Nigeria, as is the case in many countries around the globe, a major concern in the assessment of skill-based Health Education in particular and assessment in general is that these assessment procedures have no bearing on assessing Twenty-First Century skills. While addressing the Nigerian Economic Summit Group on Wednesday, March 19, 2014, a former Vice-President (African Region) of the World Bank and former Minister of Education, Mrs. Obiageli Ezekwesili decried the present assessment format in Nigeria and identified Nigerian examination system as obsolete and a major pit fall in the Nigerian educational sector[7]. Assessment practice needs urgent change as the Nigerian education system must not ignore assessing vital skills if schools are to help prepare students to meet the demands of the Twenty-First Century [7]. Routine cognitive and manual tasks, which according to Levy [8], can be performed by following a set of rules or a set of precise 
repetitive movements have declined sharply in demand as they are computerized or made extinct by the changing nature of work. The skills in greatest demand are the Twenty-First century skills - non-routine interactive skills that allow for collaborative invention and problem solving [9]. Health Education teachers are, therefore, urged to weave these skills into the teaching and testing of skill based Health Education.

This integration is important because whether a student decides to enter the workforce directly or to pursue higher education, success in the Twenty-First century according to Binkley et al. [10], lies in being able to communicate, share and use information to solve complex problems; adapt and innovate in response to new demands and changing circumstances, marshal and expand the power of technology to create new knowledge and expand human capacity and productivity. Another worrisome issue in the prevailing assessment procedure is that many assessments are focused on lower-order skills (knowledge, comprehension and application). This creates surface knowledge and opportunities to memorize and regurgitate facts. However, Twenty-First century assessment must include higher-order skills. Higher order skills based on Bloom's Taxonomy of Cognitive Skills as enumerated by Darling-Hammond and Adamson [9] include: analysis, which entails learners ability to examine arguments, make inferences and find evidence that supports explanations; synthesis, which is centered on learners' ability to compile information in different ways to produce a new pattern or alternative solution; and evaluation, which deals with learners' ability to weigh and balance evidence, evaluate ideas based on rigorous standards, present and defend ideas based on their judgments about information.

The implication is that, Twenty-First Century skills require deep understanding of subject matter. Willingham [11] stated that this deep understanding involves knowing all the facts and knowing how they fit together. This is against the background that ability to recall pieces of information is no longer the most important learning outcome; what is more important is the ability to use information to solve problems [12]; which is the very essence of skill based Health Education. Thus, assessment of Twenty-First century learning outcomes focuses more on students' operational skills, such as their expertise in using multiple sources appropriately and efficiently rather than on whether or not a correct response was submitted [12].

Indeed, assessment of Twenty-First Century skills would rely more on tests that present students with rich real-world tasks and require them to craft their own responses, perform an activity or produce a product rather than merely selecting multiple choice answers. Twenty-First Century assessments should show students' thinking, ability to explain their thinking, and use of higher-order skills. Multiple choice tests which are common assessment tools in Nigeria, according to Stecher [13] do not reflect the nature of performance in the real world. The health challenges facing Nigeria and Africa today such as global warming, promiscuity, substance abuse,
STI threat, rape, sexual violence and violence against women and children certainly do not present people with four or five distinct choices. Instead, solving these problems requires critical analysis and evaluation of the many complex issues around them. In fact, people need to think in terms of the underlying systems and their sub-systems to overcome these challenges.

It is thus pertinent that Twenty-First Century teaching and assessment of skill based Health Education be refocused on operational skills to help prepare Nigerian children to be genuinely ready to face the realities of their future. However, literature indicate that the Twenty-First Century skills like collaboration and creativity are difficult to assess [14] .In addition, the skills are highly dimensional in nature and Health Education teachers need to understand the dimensions and decompose them to levels of specific measurable skills, which will then permit them to make inferences and diagnosis about levels of the skills.

\section{Assessing Skill-based Health Education}

Assessment in skills-based health education focuses on the development of key knowledge, attitudes and skills, which can be expected to influence the development of health-promoting behaviors in real life. As earlier stated, the current predominant assessment procedure in Nigeria is focused on knowledge thereby leaving out attitude and skills. It is important that all these objectives - knowledge, attitudes, and skills are assessed, as assessment of knowledge alone is not sufficient to attain behaviour change in learners which is the overall aim of Health Education.

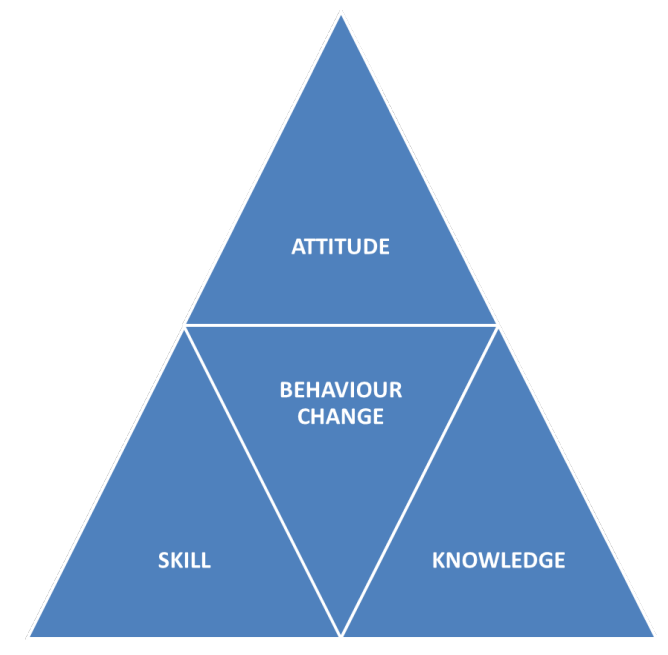

Skill-based Health Education Model (Source: Authors)

The model above shows the vital components of skill-based Health Education that assessment effort must cover. At the centre of the model is behaviour change which is the very essence of Health Education. When adequate knowledge and requisite skills have been acquired and positive attitude towards that particular health practice, 
behavior change is very likely to occur. Understanding this model and its workings has significant and relevant implication for the teaching of skill-based Health Education as the health teacher can only assess what has been taught. From the model, the Knowledge component refers to what students understand and have learned, both prior to being exposed to a curriculum and after it. It must be stated that this knowledge is functional and must be something that can be put into use in preventing disease and protecting health.

Skills refer to students' abilities to carry out specific behaviors. These are often called "life skills", because they are the interpersonal and thinking skills that enable students to handle issues that they face in real life. Skill objectives for skills-based health education with an HIV prevention focus might include being able to problem-solve when faced with decisions on health-related matters, being able to communicate assertively when faced with pressure to have intercourse, and being able to use condoms correctly.

Attitudes refer to feelings, values and beliefs that are held about the self, others, and issues. Attitudes are influenced by cultural and religious teachings, as well as school, the peer group, parents, and life experience. Attitude objectives for skills-based health education with an HIV prevention focus might include a positive self-image regarding bodily changes during puberty, motivation to engage in healthy behaviour, a sense of concern for those affected by HIV/AIDS, and willingness to consider alternatives to intercourse.

Behaviors refer to what young people actually do when confronted with decisions about health-related issues. Behavioral objectives for skills-based health education with an HIV prevention focus might include refusal to share needles if injecting drugs, consistent use of condoms when having intercourse, and delaying the age of first intercourse.
This positive behavioral outcome can be anchored on the possession of functional knowledge of HIV transmission, a positive attitude towards HIV prevention as well as the possession of the requisite skills for HIV prevention. Typical examples of such social skills are assertiveness and refusal skills required in politely turning down premarital sexual advances as well as negotiation skill in negotiating consistent and correct condom use.

\section{Assessing Knowledge Objectives in Skill-based Health Education}

Assessing knowledge involves determining what students understand and have learnt. Assessing knowledge is essential in skills-based health education. However, caution must be used in interpreting results of knowledge assessments. The ability to recall information is not necessarily the same as comprehension and application, which requires the students to understand how the information can be used in new situations. Acquisition of knowledge alone does not guarantee an influence on behaviour, which is the ultimate aim of Health Education.

For many teachers, assessing knowledge is easier than assessing skills or attitudes. The tools widely used to assess knowledge - true-false tests, multiple choice questionnaires, sentence completions, short answer tests - are familiar to most teachers. Because knowledge is usually assessed according to whether answers are right or wrong, these tools lend themselves to teacher assessment. Questions must assess what students really know, rather than eliciting the answers that students think the teacher wants to hear. Some criteria for the construction of good questions are summarized in the table below.

Table 1. Criteria for Assessing Knowledge Objective in Skill Based Health Education

\begin{tabular}{|c|c|c|}
\hline CRITERIA & BAD EXAMPLE & GOOD EXAMPLE \\
\hline Questions should be clear and unambiguous & How can you plan diet? & $\begin{array}{l}\text { How can you plan the diet of a pregnant } \\
\text { woman? }\end{array}$ \\
\hline $\begin{array}{c}\text { Only questions that learners reasonably know } \\
\text { the answer should be asked, i.e. } \\
\text { information that has been covered in } \\
\text { class }\end{array}$ & $\begin{array}{l}\text { List, in order, the three most common sexually } \\
\text { transmitted infections in Nigeria today. }\end{array}$ & $\begin{array}{l}\text { Name an infection that can be sexually } \\
\text { transmitted. }\end{array}$ \\
\hline $\begin{array}{c}\text { Question items must be short and not } \\
\text { overloaded }\end{array}$ & $\begin{array}{c}\text { True or False: It is safe to care for a person with } \\
\text { AIDS if you take precautions such as not } \\
\text { coming into contact with open sores or } \\
\text { body fluids, wearing latex gloves if you } \\
\text { might come into contact with body } \\
\text { fluids, } \\
\text { and disposing of gloves and other soiled items } \\
\text { properly }\end{array}$ & $\begin{array}{c}\text { True or False: If you are caring for a person } \\
\text { with AIDS who has open sores, } \\
\text { wearing latex gloves will prevent the } \\
\text { spread of HIV. }\end{array}$ \\
\hline $\begin{array}{l}\text { Biased items must be avoided in question } \\
\text { construction }\end{array}$ & $\begin{array}{l}\text { People with loose sexual morals have an } \\
\text { increased risk of }\end{array}$ & $\begin{array}{l}\text { People who have unprotected sex with } \\
\text { multiple partners have an increased } \\
\text { risk of }\end{array}$ \\
\hline $\begin{array}{c}\text { Avoid double-barreled questions (those that } \\
\text { ask for a single answer to a } \\
\text { combination of questions). }\end{array}$ & $\begin{array}{l}\text { True or False: A girl cannot get pregnant if she is } \\
\text { using birth control pills, but she can still } \\
\text { get infected with HIV. }\end{array}$ & $\begin{array}{l}\text { True or False: Birth control } \\
\text { pills provide protection against HIV. }\end{array}$ \\
\hline
\end{tabular}

Source: Modified from Fountain, S and Gillespie, A (2003). Assessment Strategies for Skills- based Health Education with a focus on HIV prevention and related issues. UNICEF Education Section, New York. 


\section{Assessing Attitude Objectives in Skill-based Health Education}

Attitudes, or how learners feel about health issues they have been exposed to through health instruction are critical factors that have overwhelming influence on behavioral modification. UNESCO [15] observed that learning that addresses knowledge alone, without affecting attitudes, emotions, perceptions, intentions, and motivations is unlikely to influence behaviour. It should however be noted that unlike knowledge, assessing and quantifying attitude directly is extremely difficult. Attitude can be easily inferred from behaviour as often the presence or absence of certain attitudes is inferred through observing behaviour. For instance, if a young person consistently engages in the sanitation of his environment, he is deemed to have positive attitude to environmental health and takes responsibility for his personal health and that of others in his environment.

However, there are "proxy" measures that may be especially important for assessing the domain of attitudes. For example, tools that assess intentions can reveal student attitudes, and are one of the best predictors of future behaviour. Tools that assess students' perceptions of social norms - for example, what friends are doing with regard to sexual behaviour, condom use, smoking, alcohol use can also reveal attitudes, and may be predictive of future behaviour. This is predicated on the fact that most adolescents want to "fit in" with their peer group, what students think friends are doing affects their behavioral choices.

Although self-reporting measures like Likert scales, sentence completion tasks and interviews have been found to effectively measure attitude and are commonly used, teachers/assessors must note that students may respond on self-reporting measures in a way that reflects what they think the teacher wants to hear, rather than what they actually feel. It is therefore important to take cognizance of this while interpreting attitude result on self-reported measured designed to assess attitude. For instance, if an attitude score reveals a positive attitude towards alternatives to penetrative sexual intercourse (e.g. hugging or masturbation), that does not mean that the alternative would be practiced by the learners.

When assessing attitudes, triangulation, which entails the use of more than one method of assessing the achievement of an objective is particularly important. In skill based Health Education, assessing attitude should therefore not be solely based on the teacher's assessment tools but also assessment tools that involve self, peer, or even parent assessment, in order to gather information on attitudes from as many sources as possible.

\section{Assessing Skill Objectives in Skill-based Health Education}

Skills refer to student abilities which can support behaviors. It is essential to evaluate skills in skills-based Health Education programmes because skills are required to empower knowledge and positive attitude to engender behaviour change. Students who have developed and performed specific skills in the classroom are more likely to behave outside that classroom in ways that are conducive to health and well-being. There is a range of different skills that should be assessed in skills-based Health Education. If for instance, the focus of the intervention is on HIV/AIDS, specific programme skills, such as the ability to safely care for a person living with AIDS, or the ability to accurately assess risk must be assessed. Others are psychosocial skills such as the ability to solve problems, communicate assertively, or use critical thinking skills to analyze situations.

Different assessment tools are considered appropriate for different types of skills. It should be noted that skills are often assessed through demonstration or observation. But in assessing skill development for HIV/AIDS prevention, the critical skills needed often cannot be observed in the artificiality of the classroom setting. While students may use skills effectively in a lesson, there is no guarantee that those skills will be used in actual situations where peer pressure, threats, or other factors may influence their use. Self-report instruments are another commonly used means of assessing skills, but students using them may over- or under-estimate their skills, or report what they think the teacher wants to hear. As is the case in assessing other domains of learning such as knowledge and attitudes, it is important to triangulate, or use more than one type of instrument to gather information on students' skill levels.

The use of peer assessment strategies may be particularly effective for skill assessment. An adult's evaluation of a student's abilities to negotiate for less risky behaviour, for example, may be based on what adults consider important criteria. This may have little relationship to what actually works when young people must make decision about sexual behaviour. Students themselves are more likely to be able to determine whether or not a particular strategy will really work, and under what circumstances.

\section{Assessing Behaviour Change Objectives in Skill-based Health Education}

Influencing behaviour is a complex process, and is therefore the major objective of skills-based Health Education. Since behaviour modification is complex and follows a defined pathway thus requiring time to be perfected, objectives range from short, medium to long-term. Therefore, the development and maintenance of new behaviors takes time, and behavioral outcomes in skills-based Health education will not take place where they can be witnessed and measured by the classroom teacher.

According to Fountain and Gillespie [3], measures of the extent to which behaviour has been influenced are generally not a major component of classroom-based assessment. Behaviour change or development measures are more likely to be used in programme evaluation, as an indicator of the success of a skills-based Health Education programme. However, approaches to assessing the degree to which behaviour has been influenced are discussed below to provide a picture of the larger goals of evaluating life skills 
education.

Development of behaviour change assessment tools as well as interpreting results from these tools must be done with some level of caution. This is because many tools for assessing the extent to which behaviour has been influenced ask young people to self-report about their own behaviour. It should be borne in mind that self-reporting is not always reliable; if the behaviour being assessed is perceived by students as being socially desirable, they are likely to report that they do it, whether or not they actually do.

Additionally, the fact that assessment tools indicate that behaviour has been influenced does not prove that it is the skills-based Health Education programme that has brought about the change. Education is but one factor that contributes to change. Social policies, the media, practices of health care systems, peer pressure, and parents are a few of the other contributors [3]. This must be taking into consideration while evaluating the impact of an intervention targeted at a particular behaviour among a target group.

\section{Conclusions}

This paper reviewed the defect in the present assessment system for skills-based Health Education for young people in Nigeria. The present assessment system in Nigeria lacks assessment of significant parameters indicative of success in the Twenty-First Century. Various skills and competencies required to make advancement in an information, communication, creativity and innovation driven century are lacking in Nigeria's current assessment system. Since skills-based Health Education was introduced in the beginning of the Twenty-First Century as a responsive tool to peculiar health challenges of the century, assessment tools and procedures useful in assessing this programme must be developed and utilized.

\section{Recommendations}

The defect in present assessment procedures for skill-based Health Education in Nigeria calls for a paradigm shift since the present assessment tools and systems are not appropriate in assessing the goals and objectives of skills-based health Education which are drawn from educational goals and objectives of the Twenty-First Century. As a responsive strategy to this, salient points and strategies to ensure proper assessment of skills-based Health Education discussed in this paper must be adopted. However, the under listed points must be noted:

\section{Capacity Building for Health Education Teachers}

There must be conscious efforts to re-tool, re-train and re-equip classroom teachers on the expectations of the society in a new century that has peculiar educational demands and tasks. Teachers play a significant role in ensuring that Nigerian students are equipped with the knowledge and skills to meet the challenges of the Twenty-First Century. However, many teachers in Nigeria are not adequately equipped with Twenty-First Century skills and knowledge hence will be unable to teach and assess Twenty-First Century skills. Teacher preparation programmes must as a matter of necessity inject Twenty-First Century skills in their preparation of programme and in-service training can be used to equip those already on the field.

\section{Provision of Twenty-first Century Enabling Classroom and School System}

It is also very important to point out that the Nigerian educational system is not supportive of a Twenty-First Century learning and assessment environment. A century driven by ICT should have classrooms with ICT facilities and equipment but the reverse is the case. Schools should be supported to build technology rich centers that permit students to use the facilities until later hours. This will create access for students who do not have ICT facilities at home. In the same vein, local governments and communities should build these centers of excellence in their communities to give their children the opportunity of becoming technologically literate. Business organisations and multinational companies should also consider building such centers in the communities where they operate as a corporate social responsibility.

\section{REFERENCES}

[1] Green L, Kreuter M. (1991) Health promotion planning: an educational and environmental approach. Palo Alto, California, Mayfield Publishing.

[2] Clarke B. (2002) Designing effective health education programs. Presentation at the Rural Health Institute, Talladega, Alabama, 7 November 2002. http://srdc.msstate.edu/trainings/presentations_archive/2002 /2002 clarke_designing.pdf. Accessed 20 April 2013

[3] Fountain, S and Gillespie, A (2003). Assessment Strategies for Skills-based Health Education with a focus on HIV prevention and related issues. UNICEF Education Section, New York.

[4] Kizlik, B. (2013). Measurement, Assessment, and Evaluation in Education. Retrieved January 23, 2013 from http://www.adprima.com/measurement.htm

[5] Lyman, P. \& Varian, H. R. (2003). How Much Information. School of Information Management and Systems, University of California, Berkeley. Retrieved January 11, 2014, from http://www.sims.berkeley.edu/how-much-info-2003/

[6] Mandell, L. J. (2011): World's Data Doubles Every Two Years, Creating Mega Job Opportunities. Retrieved 30 November, 2013 from http://jobs.aol.com/ articles/2011/06/29/worlds-data-doubles-every-two-years-cr eating-mega-jobopportunities/ 
[7] The Nigerian Economic Summit Group (2014). Closing Summary of the $20^{\text {th }}$ Nigerian Economic Summit Group, Abuja Nigeria. Retrieved online from http://www.nigerianeconomicsummit.org/images/NES20_Cl osing\%20Summary_19.013.14.pdf

[8] Levy, F. (2010). How Technology Changes Demands for Human Skills. OECD Education Working Paper No. 45. Retrieved January, 242014 from http://www.oecd.org/edu/skills-beyond-school/45052661.pdf

[9] Darling-Hammond, L. \& Adamson, F. (2010). Beyond Basic Skills: The Role of Performance Assessment in Achieving 21st Century Standards of Learning. Stanford, CA: Stanford University, Stanford Center for Opportunity Policy in Education

[10] Binkley, M., Erstad, O., Herman J., Raizen, S, Ripley, M and Rumble, M. (2010). Defining 21st Century Skills. Retrieved January 24, 2014 from $h t t p: / /$ atc21s.org/wp-content/uploads/2011/11/1-Defining-21st-Cen tury-Skills.pdf

[11] Willingham, D. (2008). Education for the 21st Century: Balancing Content Knowledge with Skills. Encyclopedia
Britanica Blog. Retrieved January 24, 2014 from http://www.britannica.com/blogs/2008/12/schooling-for-the21stcentury- balancing-content-knowledge-with-skills/

[12] Partnership for 21st century Skills (2007). 21st Century Skills Assessment: A Partnership for 21st Century Skills e-paper. Retrieved January 24, 2014 from

http://www.p21.org/storage/documents/21st_Century_Skills_ Assessment_epaper. pdf

[13] Stecher, B. (2010). Performance Assessment in an Era of Standards-Based Educational Accountability. Stanford, CA: Stanford University, Stanford Center for Opportunity Policy in Education.

[14] Measurement Methods Working Group, MMWG (2012): Prototype Framework for Measuring Learning Outcomes. Retrieved January 24, 2014 from http://www.brookings.edu/about/centers/universal-education llearningmetrics- taskforce/ /media/11ED8FF614AB43C0B949DD5581E68CFD. ashx

[15] UNESCO (1998).PROAP Regional Clearing House on Population Education and Communication. p. 2 